\title{
Constituição histórica do poder na mídia no Brasil: o surgimento do quarto poder
}

\author{
Historical Constitution of media power in Brazil: the emergence of the fourth power
}

\author{
Carla Candida Rizzotto
}

Mestre em Comunicação e Linguagens pela Universidade Tuiuti do Paraná (UTP), Curitiba, PR - Brasil, e-mail: carla_rizzotto@ yahoo.com.br

\begin{abstract}
Resumo
Este artigo faz parte de pesquisa de doutorado a respeito das relações comunicacionais, dos efeitos e dos contratos comunicacionais dos chamados "quarto poder", representado pela mídia, e "quinto poder", representado por experiências de resistência à influência midiática. O quarto poder, em sua origem, se referia ao papel da mídia como fiscalizadora dos demais poderes; hoje, contudo, este poder está relacionado com a articulação da agenda da sociedade e a influência política, econômica e cultural exercida. Neste momento da pesquisa, é fundamental entender como se formou tal poder. Para isso, faz-se necessário revisar a história do surgimento e evolução da imprensa no Brasil, com base em Nelson Werneck Sodré (1999) e Marialva Barbosa (2007). Com base na revisão histórico-bibliográfica, este artigo tem como objetivo mostrar que o modo como o jornalismo se constituiu no Brasil é um importante indicador da identidade política dos jornalistas, pois historicamente o jornalismo sempre esteve submetido ao poder político.
\end{abstract}

Palavras-chave: Quarto poder. História da imprensa. Concentração midiática.

\section{Abstract}

This work proposes - through the description of the tools used by Greenpeace - making notes about the means by which social movements are appropriating cyberspace to develop their activities. In addition to that, using Habermas' model of circulation of political power, we seek to highlight how Greenpeace influences the decision-making centers. The possibilities brought by the internet allowed the fragmentation of the public space, making it a diffuse and This article is part of doctoral research about communication relations, effects and communication contracts called 


\begin{abstract}
"fourth power", represented by the media, and "fifth power", represented by experiences of resistance to media influence. The fourth power, in its origin, was used to refer to the role of the media as the inspection of other powers; Today, however, this power is related to the articulation of the agenda of the society and the political, economic and cultural influence. In this moment of the research, it is critical to understand how such power has been formed. To do this, it is necessary to review the history of the emergence and evolution of the press in Brazil, supported by Nelson Werneck Sodré (1999) and Marialva Barbosa (2007). Through historical and literature review, this article aims to show that the way the journalism was established in Brazil is an important indicator of political identity of journalists, because historically the journalism has always been subjected to political power.
\end{abstract}

Keywords: Public space. Social movements. Greenpeace.

\section{Introdução}

Várias características do mundo contemporâneo são resultado de um conjunto de transformações que tiveram início ainda na Idade Média. A relação de poder desempenhada pelos meios de comunicação de massa é um exemplo disso. Para tratar desse assunto é fundamental iniciar este artigo discorrendo a respeito das transformações econômicas, políticas e simbólicas que definiram a situação atual.

No campo econômico cabe destacar a transformação do sistema feudalista para o capitalista por volta de 1450, que se deu gradualmente mediante o crescente uso das redes de trocas. As empresas capitalistas se desenvolveram ao longo dos séculos seguintes, favorecendo a Revolução Industrial nos séculos XVIII e XIX, que, ao desenvolver novos métodos de produção, aumentou a capacidade de produção das empresas. No campo político, a organização dos Estados variou muito de uma região para outra, prevalecendo a forma absolutista, em que o poder era concentrado nas mãos do monarca. Na Inglaterra, entretanto, o poder do monarca foi moderado graças ao papel da oposição e à separação dos poderes, o que ajudou a desenvolver a democracia liberal, representativa e multipartidária, em voga em muitos estados até hoje (THOMPSON, 2008).

O que mais nos interessa, entretanto, são as transformações pelas quais o poder simbólico passou. Inicialmente na mão da Igreja Católica Romana, ele foi fragmentado com o advento do protestantismo no século XVI. Nesse mesmo período houve uma importante expansão dos sistemas de conhecimento, que fez com que a ciência fosse valorizada, adquirindo também o poder simbólico. Mas foi o advento da imprensa, e, consequentemente, das indústrias da mídia, o grande responsável pela reorganização do poder simbólico. A sobrevivência dessas indústrias dependia da mercantilização de formas simbólicas, o que fez com que novos centros de poder simbólico surgissem fora do controle do Estado e da Igreja.

É este fato que permite que hoje existam referências à mídia como quarto poder, e é sobre a constituição do poder da mídia brasileira que este artigo tratará.

\section{Por que quarto poder?}

Para discorrer a respeito do quarto poder, é importante atentar para algumas diferenças conceituais. Albuquerque (2009) explicita três diferentes concepções: o modelo Fourth Estate, o modelo Fourth Branch e o modelo de Poder Moderador, mais comumente adotado nas pesquisas brasileiras. O primeiro modelo, Fourth Estate, não se refere ao "quarto poder" como alternativa aos poderes executivo, legislativo e judiciário, mas sim à organização feudal em torno de três estados formadores do Parlamento: o Clero, a Nobreza e os Comuns. Sendo assim, a imprensa como "quarto estado" estaria representando os interesses do restante da sociedade, ou seja, o papel da imprensa seria tornar público temas antes só restritos ao Parlamento. Esse modelo teve seu prolongamento representado pelo termo "watchdog" (cão-de-guarda), que originou uma contrametáfora por parte de Donohue, Tichenor e Olien (apud ALBUQUERQUE, 2009): "lapdog", ou "cachorro-lambão", representando 
a submissão à autoridade e a total falta de poder independente. Como meio-termo os autores sugerem a utilização do termo "guard-dog", que explica uma imprensa a princípio dependente dos grupos dominantes, mas que pode se revelar mais crítica quando pedirem as circunstâncias.

O segundo modelo explicado por Albuquerque (2009) é o Fourth Branch, que remete, agora sim, à divisão dos poderes executivo, legislativo e judiciário, garantindo à imprensa um papel de publicização de certos temas em detrimento de outros, e, portanto, o poder de determinar a agenda pública, conhecido como agenda setting.

O último modelo, de Poder Moderador, também se refere à divisão dos três poderes, mas propõe como solução a criação de um quarto poder neutro, denominado pouvoir royal. Esse modelo serviu como referência para a Constituição de 1824, que enfatizou três concepções do Poder Moderador: caracterizando o lugar privilegiado ocupado pelo imperador; definindo-o como um poder de exceção ou vendo-o como um recurso de centralização política. Isso fez com que a Coroa brasileira governasse acima das facções políticas no Primeiro Reinado e como árbitro do jogo político no Segundo Reinado (LYNCH apud ALBUQUERQUE, 2009). Com a mudança do regime em 1889, o Poder Moderador teve fim; contudo, foi exercido de maneira equivalente quase um século mais tarde pelas Forças Armadas, ao reivindicarem para si o papel de "guardiãs" da ordem constitucional. Albuquerque (2009) explica que a imprensa, ao se tornar politicamente ativa, assemelha seu papel ao do Poder Moderador, mas ressalva que ele não é constitucionalizado, mas simplesmente um papel que ela se dispõe a desempenhar.

Colocadas as diferenças entre os três modelos, ainda é necessário expôr a forma de atuação da mídia na América Latina. Hallin e Mancini (2007) explicam três principais padrões de desenvolvimento da mídia nas democracias ocidentais: o modelo pluralista polarizado, o modelo corporativista democrático e o modelo liberal. Essa classificação é feita com base em quatro pontos principais: (a) o nível de desenvolvimento dos mercados de mídia; (b) o grau de paralelismo entre os sistemas midiático e político; (c) o nível de profissionalismo no jornalismo; e (d) o nível e a natureza da intervenção do Estado nos meios de comunicação.

O modelo corporativista democrático se caracteriza pela forte autorregulamentação, pela intervenção do Estado e por uma presença marcante do setor público nas transmissões de rádio e televisão. O modelo liberal se caracteriza por ser um sistema muito mercantilizado com intervenção pública limitada e uma presença pequena do chamado "paralelismo político". A imprensa do modelo pluralista polarizado, por sua vez, se diferencia por estar focada em audiências de alto nível educacional e politicamente ativas, tendo, portanto, um alto paralelismo político que possibilita que cada veículo assuma uma clara identificação ideológica. Esse papel é causa ainda da pequena participação do Estado na regulação dessas atividades.

Albuquerque (2008), porém, promove uma releitura dos conceitos propostos por Hallin e Mancini mais adequada à realidade brasileira, especialmente levando em conta a questão do paralelismo político, que diz respeito ao grau de proximidade entre os meios de comunicação e as forças políticas. O autor explica que o problema existente é pensar o paralelismo como uma variável em si mesma, quando ele, na verdade, resulta da combinação de duas variáveis: as características do sistema midiático e do sistema político. A ressalva feita por Albuquerque (2008) é que Hallin e Mancini não levam em consideração as características do sistema político, pois seu corpus de análise é bastante homogêneo, são países europeus parlamentaristas, nos quais os partidos políticos possuem um papel importante.

Sendo assim, partindo de duas considerações - os modelos apresentados por Hallin e Mancini não são adequados à realidade brasileira e a conceituação de paralelismo político utilizada por eles não abrange a organização das instituições políticas, mas somente das midiáticas -, Albuquerque (2008) propõe um novo ponto de partida para classificar o modelo midiático dos países. O modelo surge do cruzamento de duas variáveis: "a primeira diz respeito ao grau de estruturação do sistema partidário, tendo em vista o grau de influência que as clivagens partidárias exercem junto ao governo e à vida política como um todo; a segunda se refere ao grau de intervenção dos meios de comunicação 
nos assuntos políticos." (ALBUQUERQUE, 2008, p. 12). E é assim constituído:

\begin{abstract}
Sistema Partidário FortementeEstruturado - Mídia Politicamente Ativa: este modelo corresponde ao modelo "pluralista polarizado", nele os meios de comunicação se apresentam como representantes dos partidos políticos, com diferenças bem definidas entre eles.

Sistema Partidário Fortemente Estruturado - Mídia Politicamente Passiva: corresponde ao modelo "corporativista democrático", no qual os meios de comunicação até apresentam vínculos partidários, mas não possuem a atuação política como objetivo principal.

Sistema Partidário FracamenteEstruturado - Mídia Politicamente Passiva: equivalente ao modelo "liberal", possuem nos Estados Unidos seu melhor exemplo. Neste caso os meios de comunicação rejeitam os compromissos políticos, mantendo-se fiel apenas aos compromissos ideológicos comerciais.

- Sistema PartidárioFracamenteEstruturado - Mídia Politicamente Ativa: esta classificação corresponde aos países que possuem um sistema partidário com pouco impacto sobre a sociedade. Para substituir o papel dos partidos então, duas instâncias podem ser solicitadas: o Poder Executivo, na figura do líder carismático - como é o caso do ex-presidente Lula no Brasil, e do presidente Hugo Chávez na Venezuela -, e (ou) a mídia, como agente especializado.
\end{abstract}

Mas é claro que essa classificação precisa ser contextualizada. Os estudos preliminares a esta pesquisa permitiram notar que nos dias de hoje, quando se fala em mídia como quarto poder, não se está mais falando sobre seu papel de fiscalizadora dos demais poderes, mas como articuladora da agenda da sociedade. Quer dizer, o quarto poder, considerado o mais adequado para controlar os demais em nome da cidadania e da democracia, acabou por ser o mais poderoso e o menos controlável, já que se vincula com as forças de geração de demanda, a publicidade, modelando as condutas e as consciências de acordo com o que a economia de mercado determina (SODRÉ, 1994). De representante do público nas discussões políticas, o quarto poder exercido pela imprensa se tornou inibidor do papel ativo do público.

Percebe-se, então, que "a mídia, mesmo nas nações integradas tecnologicamente ao final do segundo milênio, permanece um baluarte das elites" (SILVA, 2000, p. 19), e que, assim como ela, os demais grupos, organizações e instituições do Estado visam ao exercício do poder, ou no mínimo, "à hegemonia dentro do organismo social e pretendem sempre, direta ou indiretamente, influenciar a ação governamental e orientar o sentido das transformações sociais" (BELTRÃO; QUIRINO, 1986, p. 90). Miguel (2002) mostra, porém, que essa constatação não significa que a sociedade deve se conformar com a situação, é certo que a mídia sempre vai defender determinados segmentos da sociedade, mas as mudanças passam pela pressão e resistência dos grupos prejudicados por essa forma de gestão da comunicação.

\section{Constituição histórica das relações de poder da mídia}

O modo como o jornalismo se constituiu no Brasil é importante indicador da identidade política dos jornalistas, pois mostra como historicamente o jornalismo sempre esteve submetido ao poder político. Para tanto, Nelson Werneck Sodré e Marialva Barbosa se mostram como referência fundamental.

Sodré (1999) nos diz que a história da imprensa se confunde com a própria história do capitalismo. É da pressão em privatizar a imprensa de acordo com os valores do capital que surge o princípio da liberdade de imprensa, inicialmente na Revolução Francesa e na Revolução Americana, e também a propaganda como sinal da conexão entre a imprensa e o modo de produção de mercadorias. Assim, especialmente pelas suas técnicas de produção e circulação, a imprensa acaba por gerar a padronização do comportamento.

O período colonial é o primeiro indicador histórico dessa situação. No período colonial a imprensa e também a universidade não tiveram espaço de desenvolvimento no Brasil. Ao contrário 
das colônias espanholas, que já demonstravam uma cultura avançada, e por tal razão puderam ver precocemente desenvolvidas tanto uma quanto outra. Mas o surgimento das duas atividades se justifica unicamente pela necessidade de implantar a cultura externa e garantir o domínio realizado pela metrópole. Então, em 24 de junho de 1808 foi composta uma junta para administrar a Impressão Régia no Brasil, que tinha como tarefa gerenciar, examinar e fiscalizar tudo o que se imprimia. A imprensa já surgia no Brasil sob julgo da censura, tendo como seu marco inicial a Gazeta do Rio de Janeiro, um jornal oficial lançado em 10 de setembro de 1808; e o Correio Brasiliense, publicado em Londres por Hipólito da Costa (SODRÉ, 1999).

Os dois primeiros jornais a circular no Brasil, entretanto, não merecem atribuição importante na história do jornalismo no país, já que o primeiro era um exemplo muito rudimentar do jornal que conhecemos hoje, e o segundo era caracterizado como doutrinário.

Foi somente no período da independência, mais especificamente após o retorno da Corte para Portugal, ameaçando a volta ao regime de monopólio, que as condições políticas começaram a apontar. A ameaça de retorno a uma situação indesejada implicava a mobilização que só é alcançada com a formação de opinião possibilitada pela imprensa. Então, o movimento pela independência de 1820 foi favorável para o desenvolvimento da imprensa: em $1^{\circ}$ de junho de 1821 começa a circular o primeiro jornal informativo do Brasil, o Diário do Rio de Janeiro, que foi precursor no jornalismo de informação, mas que não se distanciou em demasia da anterior fase áulica. Foi o Diário Constitucional, de 4 de agosto de 1821, o primeiro jornal com a intenção de travar a luta política. Pouco tempo depois, em 15 de setembro de 1821, surgiu no Rio de Janeiro o Revérbero Constitucional Fluminense, que Sodré (1999) caracteriza como o órgão doutrinário da independência do Brasil, e que inicia os esforços (especialmente de luta contra a direita conservadora) para a convocação da Assembleia Geral Constituinte.

Entretanto, com a proclamação da Independência em 1822, o problema que surge é o da estruturação do Estado, os grupos politicamente divergentes começam então a disputa pelo poder, e a recém-concedida liberdade de imprensa é mais uma vez anulada pelas forças dominantes, liquidando os que se preocupavam agora não mais com a luta pela independência, mas com a luta pela liberdade.

Os periódicos surgidos entre o período da dissolução da Constituinte e da abdicação, decorrente do movimento de Sete de Abril, são "de circunstância, de combate, de linguagem virulenta, em que a historiografia oficial tem visto apenas os aspectos negativos, sem sentir neles o fecundo exemplo de sentido libertário e de avanço no esclarecimento da opinião”. (SODRÉ, 1999, p. 82). É o chamado Pasquim, imprensa panfletária que caracteriza o jornalismo da fase conturbada vivida nesse período em que a censura predominava, tendo sido abolida somente anos depois com o decreto de 28 de agosto de 1827. O Pasquim era caracterizado pela violência de linguagem, pela falta de periodicidade, por "vozes desconexas e desarmoniosas [...] combatendo desatinadamente pelo poder que lhes assegurasse condições de existência compatíveis ou com a tradição ou com a necessidade. [derivando] para a vala comum da injúria, da difamação, do insulto repetido." (SODRE, 1999, p. 157). A causa dessas características é a própria fase conturbada em que se vivia, em que se buscava o poder a partir da destruição do adversário, e, por isso mesmo, as discussões não existiam com isenção das paixões (SODRÉ, 1999).

Em 1826 foi instalada a Assembleia Geral, o Senado e a Câmara, criando condições para o aparecimento da imprensa como se conhece hoje. Eram jornais que refletiam o interesse de alguma autoridade ou algum grupo, comprovando que a imprensa sempre se desenvolveu em estreita ligação com a atividade política, acompanhando a cisão existente entre direita conservadora (representada pelos jornais áulicos ou imprensa absolutista), direita liberal (que pregava a monarquia constitucional) e esquerda liberal (representada pelos pasquins). A luta política travada pelos periódicos tinha de um lado a frente formada pelos liberais, de direita e de esquerda, que alcançou a vitória com a abdicação de D. Pedro I em sete de abril de 1831. Com a morte de D. Pedro I, porém, os liberais de esquerda se dedicaram às rebeliões das províncias, o que permitiu que os liberais de direita e os conservadores, que faziam parte do outro 
lado da luta política, buscassem a retomada do poder, que culminou com o golpe da Maioridade ${ }^{1}$ - Nesse meio tempo, o período da Regência, o Brasil viveu um período com ampla liberdade de imprensa, o que fez com que a imprensa, apesar de tecnicamente ter se mantido muito semelhante, passasse por um grande desenvolvimento político. Sodré (1999) caracteriza a imprensa existente no Brasil entre os anos de 1830 e 1850 - marcada pelos pasquins - como "o grande momento da imprensa brasileira", pois, apesar de artesanal, com distribuição restrita e pouca técnica, exerceu grande influência no cenário político.

Nessa fase, auge do poder imperial, foram raras as vezes em que a imprensa tratou de problemas objetivos, porém, na fase seguinte, conhecida como agitação, a luta política volta a se intensificar e a imprensa volta a participar dela. Entre 1870 e 1872 surgiram mais de vinte jornais republicanos no país, entre eles, $A$ República, órgão do Partido Republicano Brasileiro, fazendo com que a ideia republicana se ampliasse e alcançasse os estudantes e intelectuais. Nos anos seguintes, outros dois acontecimentos importantes para a imprensa: em 1874 surgiu a primeira sucursal da agência de notícias Reuter-Havas, que permaneceu por 71 anos no país e passou a se chamar FrancePress após a Segunda Guerra Mundial; e em 1876 surgiu a Revista Ilustrada, o maior documentário ilustrado da época.

A imprensa dessa época era, então, republicana e abolicionista, mas continuava se confundindo com a literatura, o que mostra que sua linguagem e seu papel ainda não estavam estabelecidos. Após a mudança do regime em 1889, a imprensa do país passa a ser dividida em dois grupos: de um lado grandes jornais com organização material, que já viviam da publicidade, e estavam, por isso mesmo, organizados como empresa comercial que tinham como objetivo ampliar sua participação em número de leitores; de outro, os jornais de partidos, que vivem com a ajuda dos partidos e não são, de maneira nenhuma, empresas. O surgimento do Jornal do Brasil, em 1891, marca na imprensa brasileira a substituição da imprensa artesanal (que continuava existindo no interior) pela imprensa industrial, aproximando-a dos padrões de uma sociedade burguesa: "o jornal ingressara, efetiva e definitivamente, na fase industrial, era agora empresa, grande ou pequena, mas com estrutura comercial inequívoca. Vendia-se informação como se vendia qualquer outra mercadoria" (SODRÉ, 1999, p. 275).

Essa transformação está ligada à ascensão da burguesia e ao avanço do capitalismo na virada do século. Algumas características da imprensa da época podem ser traçadas. Em primeiro lugar, a modernização. As tecnologias permitiram que os jornais aumentassem a tiragem, a qualidade e a rapidez de impressão, além disso, elas alteraram as concepções temporais e espaciais, fazendo com que "o mundo se [tornasse] mais compacto" e que "a temporalidade [ganhasse] nova dimensão" (BARBOSA, 2007, p. 23). Uma segunda característica é que os jornais se preocupavam muito mais com o fato político do que com a política propriamente dita. O que quer dizer que as questões pessoais eram muito mais valorizadas, gerando a individualização e personalização de todas as discussões, tanto por parte da imprensa de oposição quanto da imprensa de apoio, o que faz com que as alterações verificadas na nova imprensa em relação ao texto sejam mínimas, ele continua mantendo a forma dos pasquins. Além do que, continua a ser confundido com literatura (SODRÉ, 1999).

Anos depois, após o início da Primeira Guerra Mundial, a imprensa proletária se desenvolve, causando alguns contrapontos. Primeiramente, dividindo a pequena imprensa em dois tipos: a do interior, pequena por condições materiais - e ainda sem estrutura empresarial-, que não interfere na estrutura do país e nem da grande imprensa; e a de também poucos recursos materiais e circulação reduzida, mas com uma marcada posição de combate à estrutura vigente. E, ainda, dividindo a imprensa em classes: a grande imprensa da classe dominante - que trata principalmente do tema político, neutralizando a linguagem literária, mas ainda não dando espaço para a linguagem

1 O golpe da Maioridade foi a antecipação da maioridade de Pedro II, dando início ao Segundo Reinado, que durou de 1840 a 1889 
jornalística específica - e a pequena imprensa da classe dominada (SODRÉ, 1999).

Essas contradições se acentuam com a compra do O Jornal por Assis Chateaubriand ${ }^{2}$, em 1925; os jornais, que já estavam organizados como empresa, passam a se organizar em grupos empresariais. A imprensa com estrutura empresarial já surge dependente do governo, como confirma Barbosa (2007, p. 85):

Nesse cenário de mutações econômicas, políticas e tecnológicas, a imprensa continua dependente dos favores e favorecimentos oficiais para garantir a sua sobrevivência. A independência dos jornais existe apenas como discurso memorável construído pelos próprios jornalistas.

Em seu trabalho sobre a história do jornalismo do século XX no Rio de Janeiro, Marialva Barbosa (2007, p. 49 e 53) explica ainda uma outra característica dos jornais desta década: a linguagem sensacionalista, ou ainda, o "reino do "como se" _. "abandonando as longas digressões políticas, os jornais passam a exibir em manchetes, em páginas que editam, em profusão, ilustrações e fotografias, os horrores cotidianos" - que perdura, em certo grau, até hoje sob a forma do espetáculo, mesclando o "ficcional com a suposição de um real presumido", moldando assim a relação entre o leitor e o jornal.

No final da década de 1920, quando o país vivia as consequências da crise internacional, a imprensa de oposição começava a preparar uma luta política com consequências importantes: em primeiro lugar o movimento revolucionário que depôs Washington Luiz em 1930 e instalou uma junta provisória que transmitiu o poder a Getúlio Vargas, que tinha sido derrotado nas eleições; em seguida, o movimento Constitucionalista de 1932, que em 1934 conseguiu a reunião da Constituinte e a eleição de Getúlio Vargas, ainda que por via indireta. Em 1935, porém, a intentona comunista serviu de pretexto para que Getúlio Vargas impusesse o estado de sítio e a censura à imprensa, para, logo em seguida, em 1937, instaurar o regime ditatorial conhecido como Estado Novo. Nesse momento a censura criou o Departamento de Imprensa e Propaganda (DIP), que visava difundir a ideologia estadonovista por meio, dentre outras coisas, da publicidade e do controle da imprensa e do rádio, o que fez com que os jornais passassem a servir à ditadura, mesmo que a contragosto. A imprensa livre só existia clandestinamente. E, apesar de o período ser sempre lembrado pelos homens de imprensa como um momento de total cerceamento de liberdade, Barbosa (2007, p. 103) afirma que nem toda a imprensa sofreu negativamente com o período ditatorial: "ainda que haja encampação de alguns periódicos, perseguição de outros tantos, há mais proximidades, acordos e relações conjuntas entre os homens de governo e os homens de imprensa do que divergências". A construção do consenso por parte do governo se dá pelo emprego de estratégias como subsídio de papel e isenção de Imposto de Renda dos jornalistas, por outro lado, para os que não colaboram com o regime, as pressões ocorrem também por meio da forma econômica, com a negação de subsídios e de verba publicitária.

O Estado Novo só começou a se deteriorar em 1942 com a entrada do Brasil na Guerra, e assim a imprensa pôde, aos poucos, retomar suas manifestações, até que com o fim do regime, em 1945, voltou a se estabilizar (BARBOSA, 2007).

Os anos de 1950 marcaram além de mudanças administrativas, principalmente mudanças técnicae profissional no modo de fazer jornalismo, que adotou a modernização como palavra de ordem. A partir da influência norte-americana, a imprensa se desligou das esferas literária - modelo francês de jornalismo em que os gêneros livres e opinativos possuíam maior valor - e política - já que os jornais, com escassos recursos econômicos, eram porta-vozes dos grupos políticos que os financiavam - , ao adotar o ideal da objetividade, formalizado por novos procedimentos

\footnotetext{
2 Outros veículos foram comprados em seguida, formando os Diários Associados. No seu auge, na segunda metade do século XX, os Diários Associados eram formados por 36 jornais, 18 revistas, 36 rádios e 18 emissoras de televisão.

"[...] o jornal segue falando sobre o mundo como se fosse real, como se o fato relatado tivesse acontecido daquela forma, como se tivesse existido. Neste sentido é que podemos dizer que o mundo das coisas contadas é sempre do reino do 'como se' da ficção e a experiência irá depender sempre da voz narrativa que contém uma multiplicidade de vozes: a voz do autor e de todos aqueles que são designados pelo ato de narrar.” (BARBOSA, 2007, p. 65).
}

Rev. Estud. Comun., Curitiba, v. 13, n. 31, p. 111-120, maio/ago. 2012 
técnicos de redação jornalística, como o lead e a pirâmide invertida (RIBEIRO, 2003). O jornal Última Hora de Samuel Wainer é constantemente lembrado como marco dessas realizações.

Nos Estados Unidos, o jornalismo informativo surgiu a partir da popularização dos periódicos e da transformação dos jornais em empresas, assim, os jornais, na tentativa de se tornarem mais referenciais, deixaram de assumir explicitamente suas posições ideológicas. No Brasil,

observa-se, pois, que as bases para a construção do ideal de objetividade do jornalismo, que seriam aprofundadas com as reformas por que passariam os jornais cinquenta anos mais tarde, estão lançadas na virada do século XIX para o XX. A rigor, o mito da objetividade deve ser percebido na longa duração, como um simbolismo construído pelas próprias empresas jornalísticas e pelos jornalistas para assim cunhar uma distinção, no sentido que confere a esta palavra Bourdieu (1989), ou um lugar autorizado de fala (BARBOSA, 2007, p. 40).

Conforme explica Ribeiro (2003), o jornalismo aqui estava muito próximo da política e ainda se constituía como uma atividade literária, foi somente a partir da década de 1950 - com o advento do copy-desk e do ensino acadêmico do jornalismo - que a objetividade se tornou um padrão. Ribeiro (2003) afirma que a objetividade transformou-se em um valor fundamental para a profissão e para a construção da identidade dos jornalistas. Quer dizer, o mito da objetividade se faz fundamental na definição do jornalismo como um campo autônomo, legitimado como atividade passível de revelar o mundo ao leitor, ou seja, reconhecido pelo público como força dirigente dotada de poder.

Por outro lado, as críticas à adoção do fazer-jornalístico norte-americano existiam em grande número. Até mesmo Jânio Quadros, presidente eleito em 1960, disse que "o gigantismo norte-americano nos é prejudicial e ridículo" (apud RIBEIRO, 2003).

Assim, objetividade e neutralidade foram ideais que transformaram a imprensa em um ator social reconhecido, mas não impediram os jornais de exercerem seu papel político, nem em 1954 com a campanha realizada pela imprensa que culminou no suicídio de Getúlio Vargas, nem em 1964, quando toda a grande imprensa se articulou para a saída de João Goulart do poder, culminando no golpe militar. As relações de poder que envolvem os meios de comunicação de massa são muito mais amplas, portanto, do que as relações estabelecidas com o Estado ou com o grupo social dominante. A mídia influencia um sistema simbólico de construção de conhecimento e assim assume um lugar de poder absoluto, pois é pela legitimidade oferecida a ela por parte do público que ela ganha o direito de codificar o mundo e as relações sociais.

Na década seguinte a televisão se populariza e passa a exercer também o papel de difusor de ideologia, tornando-se essencial para a ditadura instaurada em 1964 por transmitir a imagem de um país moderno "que só existe no discurso ideológico" (BARBOSA, 2007, p. 180). Para alcançar os objetivos visados pelo governo ditatorial, entretanto, era imprescindível que a televisão deixasse de lado o conteúdo político e priorizasse outros conteúdos em sua programação.

A censura também voltou a existir no período ditatorial, porém, assim como durante o Estado Novo, a atuação da imprensa perante ela é bastante idealizada, pois apesar da construção de um discurso heróico de combate, sua própria sobrevivência no mercado está em jogo. O que faz com que os jornais adotem constantemente a prática da autocensura, ignorando a ação repressora do regime e destacando os feitos econômicos do governo. Para Barbosa (2007), a autocensura acontece devido às vantagens que a imprensa receberia ao se alinhar aos detentores do poder político, assim, o discurso de defensores da liberdade propagado por ela não se aplica na prática e somente contribui para a ampliação do público e do seu domínio simbólico sobre ele.

Com o fim da ditadura militar, o jornalismo passou por diversas mudanças no Brasil, entre elas destacam-se a utilização das tecnologias de informática, o surgimento do jornalismo investigativo e a maior importância atribuída aos assuntos econômicos. Barbosa (2007) atribui o crescimento do jornalismo econômico à diminuição dos temas políticos devido ao regime militar, à adoção do paradigma do neoliberalismo e à consolidação do processo de globalização. Em especial essa última mudança marca o lugar dos meios de comunicação de massa como detentores de um poder simbólico, influenciados não somente pelo poder político, mas acima de tudo, pelo capital. 
A concentração excessiva dos meios de comunicação também encontra na história razões que a justificam. Foi a partir da segunda metade do século XX, com o desenvolvimento do rádio e da televisão, que as evidências começaram a aparecer. O principal exemplo são os Diários Associados, de Assis Chateaubriand, que teve o primeiro veículo, $O$ Jornal, criado ainda em 1925. Apesar de poderosas, essas empresas são profundamente dependentes de empresas estrangeiras, indicando sua vulnerabilidade. Tal vulnerabilidade se deve à grande influência das agências de notícias estrangeiras atuantes no país, que moldam as informações noticiadas de acordo com suas inclinações; e das agências de publicidade, também estrangeiras, que funcionavam como representantes dos grandes anunciantes (SODRÉ, 1999).

A influência estrangeira exercida na imprensa brasileira tem efeito também na discussão a respeito da liberdade de imprensa. Se, num primeiro momento, na fase de ascensão da burguesia, os esforços contra a censura eram direcionados exclusivamente à interferência governamental; na fase do capitalismo monopolista as empresas passam a se autocensurar, condicionadas pelo grau de dependência dos grandes anunciantes, conduzindo à transformação pela qual a imprensa passou, "de instrumento de esclarecimento, a imprensa capitalista se transformou em instrumento de alienação, fugindo inteiramente aos seus fins originários" (SODRÉ, 1999, p. 408).

Esse processoé uma expressão da "reflexividade institucional", quer dizer, é o uso sistemático de informações transmitidas à população com o objetivo de reproduzir determinado sistema social. Consiste em fazer com que os países periféricos "obedeçam" às ordens dos centrais, fazendo com que a população passe a desejar uma virtualidade que lhes é mostrada, mas que não é real. Esse processo não é ocasional, ao contrário, é vital para garantir a dominação econômica e a hegemonia política norte-americana (BELTRÃN; CARDONA, 1982).

\section{Considerações finais}

O levantamento histórico e as reflexões trazidas neste artigo mostram que um dos papéis exercidos pelos meios de comunicação desde a segunda metade do século XX é o de instrumento de legitimação da dominação capitalista. A imprensa empresarial, que surgiu quando o mundo dos negócios percebeu que podia fazer da informação uma indústria, adicionou dois novos participantes nas relações da mídia: os anunciantes e os consumidores. Conforme a imprensa foi se desenvolvendo como empresa na sociedade capitalista, menos livre ela ficou. É quando os anunciantes passam a fazer parte dessa indústria que a credibilidade passa a ser não mais uma propriedade ética, mas sim uma propriedade comercial dos jornais. Com ela surge a demanda por produtos culturais e de entretenimento, e não somente por produtos de informação, formando-se as chamadas "cultura de massa" e "indústria cultural". Com isso, os consumidores passam a ser vistos a partir de padrões de comportamento e de estilos de vida, passando por cima de barreiras geográficas e favorecendo a "mundialização" da economia. Quer dizer, assim os sentimentos de pertencimento deixam de ser determinados pela cultura nacional e passam a ser determinados pelos centros dominantes, que gestam o consumo.

É preciso tomar cuidado, entretanto, para não assumir como certa a fragilidade intelectual e moral do público, definindo-o como uma esfera passiva, e, de outro lado, assumir a maldade deliberada dos proprietários das empresas de comunicação em manipular a opinião pública. Essa discussão serve como guia para a pesquisa que pretende dar continuidade a este artigo, por meio da análise de experiências que questionam o poder da mídia: o chamado media criticism.

\section{Referências}

AlBUQUerQue, A. A mídia como "Poder Moderador": uma perspectiva comparada. Trabalho apresentado no XVII Encontro da Compós. São Paulo, 3-6 jun. 2008.

ALBUQUERQUE, A. As três faces do quarto poder. Trabalho apresentado ao Grupo de Trabalho "Comunicação e Política", do XVIII Encontro da Compós, na PUC-MG. Belo Horizonte, MG, jun. 2009.

BARBOSA, M. História cultural da imprensa: Brasil 1900-2000. Rio de Janeiro: Mauad, 2007. 
BELTRÁN SALMÓN, L. R.; CARDONA, E. F. Comunicação dominada, os Estados Unidos e os meios de comunicação da América Latina. Rio de Janeiro: Paz e Terra, 1982.

BELTRÃO, L.; QUIRINO, N. O. Subsídios para uma teoria da comunicação de massa. 2.ed. São Paulo: Summus, 1986.

HALLIN, D.; MANCINI, P. Un estudio comparado de los medios en América Latina. In: DIAZ NOSTY, B. (Ed.). Medios de Comunicación. El escenario iberoamericano. Madrid: Ariel, 2007. (Colección Fundación Telefónica). p. 91-93.

MIGUEL, L. F. Os meios de comunicação e a prática política. Lua Nova, n. 55-56, p. 155-184, 2002.

RIBEIRO, A. P. G. Memória de jornalista: um estudo sobre o conceito de objetividade nos relatos dos homens de imprensa dos anos 1950. Estudos de Comunicação Livro do XI Compós. Porto Alegre, 2003.
SILVA, J. M. A miséria do jornalismo brasileiro: as (in) certezas da mídia. Petrópolis, RJ: Vozes, 2000.

SODRÉ, M. Amáquina de Narciso: televisão, indivíduo e poder no Brasil. 3.ed. São Paulo: Cortez, 1994.

SODRÉ, N. W. História da imprensa no Brasil. São Paulo: Mauad, 1999.

THOMPSON, J. B. A mídia e a modernidade: uma teoria social da mídia. Petrópolis, RJ: Vozes, 2008.

Recebido: 25/06/2012

Received: 06/25/2012

Aprovado: 05/09/2012

Approved: 09/05/2012 